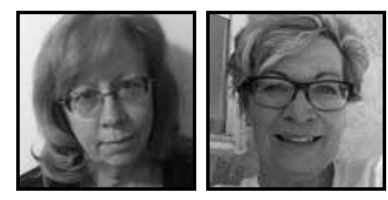

\title{
Teacher Research and Evaluation: A Story From Two Perspectives
}

\author{
Deborah Roberts-Harris and Kathy Sandoval, \\ University of New Mexico
}

\begin{abstract}
We have been fortunate to work with teachers at a 6-12 charter school who have taken the time to challenge themselves, to take a hard look at what is going on in their classrooms in terms of teaching and learning, reflect on what is working, what could be better, question how effective they are, and then share their reflections, their successes, and their doubts with each other. This project started out as voluntary and was changed to being mandatory and a part of the yearly teacher evaluation. We share our individual perspectives on this situation, and how it is unfolding.
\end{abstract}

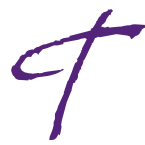

eacher research should be shared, celebrated, heard, and critiqued. The story that follows is about combining teacher research and evaluation at a 6-12 charter school in the southwestern part of the United States. This narrative begins with the opening remarks offered during the Second Annual Teacher Research Festival at the 6-12 charter school that is the focus of this article:

Being a teacher today is an act of courage; an act of courage because teachers today are facing many new challenges. Some of the challenges that we face as teachers we cannot control. Many factors are beyond our control, but we don't focus on what we can't do, but rather on what we can do. We can create classroom cultures where our students can feel safe enough to share their thinking, ask questions, make mistakes, and even fail (temporarily). We can meet the challenges of teaching individual students by getting to know them and show them we care and understand them as individuals with unique gifts and needs. 
The teachers at this school do all of these things without anyone asking-it is the norm to go above and beyond. In addition to all of this, they also take the time to challenge themselves, to take a hard look at what is going on in their classrooms in terms of teaching and learning, reflect on what is working, what could be better, question how effective they are, and then share their reflections, their successes and their doubts with each other.

The teachers sharing today are willing to put it out there-expose their weaknesses, challenges and doubts with their colleagues-and often a wonderful thing happens. They learn from each other. A calculus teacher takes an idea from a history teacher and tweaks it into something that helps his students. A PE teacher and a math teacher talk and both leave the conversation with new ideas about helping students learn. Ideas and challenges are shared. Discoveries are made and tested. Some are successful, some are not. But even when success is not immediate, learning about teaching has occurred. And that learning can only happen when teachers are willing to inquire into their own practices, and be critical of their craft, and make themselves vulnerable.

And that learning is what pushes teachers to continue to hone their craft, and become better teachers, and more effective teachers. When teachers take seriously the responsibility of learning to be better teachers the winners are the students. Because the learning that takes place in a classroom where teachers take an inquiry stance, and look deeply at their practice and their students learning, just gets better and better.

All teachers can be reflective practitioners, practitioner researchers, and study their classrooms. However not all teachers have the opportunity to do it with all of their colleagues, and without being told what and how they need to research or reflect upon. The principal at this school has made that possible with the environment she has created. She trusts the teachers to choose a question of interest to them and to pursue it, provides time for them to come together and collaborate, does not chastise those who tried something that may not have worked the first time, and then celebrates their research with them-and that's why we are here today!" (Wood, 2013)

How did this celebration of teacher research come to be? In this article, we tell the story from two perspectives, from a university faculty member (Deborah) who facilitates the teacher research process and from the school's principal (Kathy).

\section{Facilitator's Perspective}

Telling this story requires a little background. I would not have even ventured down this path, if it had not been for my previous experiences that immersed me in learning 
to do teacher research, and having teacher research become an innate part of who I am as a teacher. Below, I provide a brief description of the journey, and then share my perspective and the perspective of the principal of the charter school where teacher research has become part of the culture.

Beginning the journey. As a pre-service teacher, I was invited to participate in a teacher research group that included other novice teachers. We focused our research on science learning and teaching in our respective classrooms. The university faculty member who began and facilitated the group encouraged us to think deeply about our classroom practice and our students' learning. With support from the Spencer Foundation's Practitioner Research program, she was able to take us to teacher research conferences where we shared our findings and learned from other teachers doing similar studies in their own classrooms.

We did not realize that we were actually engaged in a process that was recommended by John Dewey (1928/1956) in Progressive Education and the Science of Education. Dewey recognized the potential of increasing knowledge about learning and teaching through reports authored by teachers reflecting on their own practices:

The method of the teacher...becomes a matter of finding the conditions which call out self-educative activity, or learning, and of cooperating with the activities of the pupils so that they have learning as their consequence ...A series of constantly multiplying careful reports on conditions which experience has shown in actual cases to be favorable or unfavorable to learning would revolutionize the whole subject of method. (pp. 125-126)

Dewey recognized that teachers who systematically reflect on their own teaching and on the learning of their students could deepen the base of knowledge and understanding for others. This would apply to university instructors as well as to classroom teachers. Reflecting on the practice of teaching, and of the students' learning through this approach, can inform others who wish to do the same.

In advocating for the experiential knowledge of teachers, Cochran-Smith and Lytle $(1993,2009)$ argue that academia is not the only place knowledge resides. In undertaking action research (Carr \& Kemmis, 1986), teachers focus on collecting data relevant to a problem they have identified and taking action, based on these data, to address the problem. Samaras (2004) describes self-study as an ongoing process that "can include looking at one's teaching self, looking at issues of teaching and learning in one's classroom, and looking at self-knowing and professional identity from a developmental 
perspective" (p. 23). Bullough and Pinnegar (2001) describe self-study as a new area of research in teacher education. They address issues of quality by stating, "its endurability as a movement is grounded in the trustworthiness and meaningfulness of the findings" (p. 20). In addition, they acknowledge two purposes, "informing practice to improve teacher education and also for moving the research conversation in teacher education forward" (p. 20).

This study provides an example of such research, which also is known as the Scholarship of Teaching and Learning (SoTL) (Boyer, 1990; Shulman, 1999, 2004). According to Shulman (1999):

A scholarship of teaching will entail a public account of some or all of the full act of teaching, vision, design, enactment, outcomes, and analysis in a manner susceptible to 'critical review' by the teacher's professional peers, and amenable to productive employment in future work by members of that same community. (p. 6)

The scholarship of teaching and learning takes us beyond reflecting on our own practices to assume responsibility for our own professional development and for improving our own teaching. The scholarship of teaching and learning further moves us toward making that practice visible to others so that it can be critically reviewed by our peers, and possibly have meaning for others in their practices (Shulman, 1999).

Learning to engage in the scholarship of teaching and learning at a very early point in my career deepened my understanding of practice. As a participant in the Carnegie Academy for the Scholarship of Teaching and Learning, I was fortunate to have become part of a national community of teacher researchers. This experience, and others, not only affirmed for me the benefit and importance of this kind of research, but also became a sustaining force in my staying in the teaching profession.

Continuing the journey. In the spring of 2011, I finished my doctorate and accepted a position at a southwestern university in teacher education. I had gone back and forth on the decision to join the academic world. I decided to go forward, but with a commitment to finding a place where I could facilitate a teacher research group. I was hoping to work with a few teachers who would be willing to ask questions about their practice and systematically collect data, and reflect on their experiences and the data. I was hoping to engage with these teachers in the scholarship of teaching and learning, which would include their sharing their findings with others. It offers a reflective and systematic approach to research and places the classroom setting and participants at the heart of the study. The focus is on a topic that teachers choose, something they 
were curious about, something working well, or some issues they had to confront. I met a doctoral student who suggested her principal might let me propose the idea of developing a teacher research group to the faculty. And so off I went to visit the principal. Astonishingly, she agreed!

The first year of doing this was interesting to say the least. I was working with a faculty of about 20 experienced teachers, 6 th to 12th grade teachers, in a local charter school. I was a little intimidated by the idea of working with secondary teachers-I have taught elementary and middle school, and had had some experiences with high school teachers, but did not feel it was my forté. The principal encouraged the entire faculty to participate and they did for our first few meetings. We met bi-weekly for about one and a half hours. After a few months, the group got smaller-there were only about 10 teachers in the group. At the spring break, we were down to six. One teacher dropped out to finish a professional portfolio, and another teacher took on an afterschool coaching position. Down to four.

I was determined to continue to the end of the year. I have to admit, that although we were down to $20 \%$ at this time, I was always motivated and inspired by the work that took place at our meetings. The energy and excitement got me through the next two weeks of acclimating to university life.

True to my SoTL experiences, one of the things I had insisted on for this group was that the teachers had to share their research project with others. We invited other staff members at the school to come (several showed up), as well as the principal, and I was able to coerce one of my new colleagues to come with me. I had required the teachers to create a multi-media portfolio of their work through Merlot.org as their final presentation. This software was originally developed by Carnegie and then taken over by the California State University System.

One by one the teachers presented the studies they had been engaged in for most of the year. The principal, with whom I had had very little interaction throughout the year, was taking copious notes. I thought the teachers' studies were deep and rich representations of their initial question, but had no idea what the principal was thinking. After each one finished, there were a few questions for the presenter, and then it was quiet. After what seemed to be an eternity, the principal said:

I have one more question. How do we replicate this with the rest of the staff? This is real professional development. I can see from what you did you learned more about your practice than you would have if I brought in a bunch of experts. 
And so replicate it we did the following year, except the principal told her staff it was required. Initially I was in a panic. This went against what I believed about teacher research and professional development, and working with teachers. However, this was not my school, I was a guest. Even though I now knew a few teachers well, and recognized many of the others, I was worried about how this mandate to do teacher research was going to affect the work, the process, and my relationships with the teachers.

The four teachers who had followed through with the project and I sat down with the principal a few days before the new school year started and discussed how things were going to go. The principal committed to not having any other kind of meeting at the time of the teacher research, which was on Friday afternoons, when students were dismissed early. No team or department meetings, no parent meetings-just, teacher research time. We were going to take attendance. She was counting teacher research projects as $10 \%$ of the teacher evaluation. Teachers who chose not to participate would not be able to earn that $10 \%$.

One of the things that had impressed the principal the most from the original four was the fact that they all commented on how the exchange of ideas and questions, and learning about their peers' research, had informed their teaching and their research. The collaboration across content areas and grade levels seemed to be a highlight for them. She saw that the community they had built was strong, and that the teachers had gained a great deal of respect for each other through the listening and sharing that had taken place. She decided to start off by creating cross-disciplinary groups. Each of the original four members was put into one of the groups to help facilitate the work.

At our first meeting the principal laid out the expectations: This is $10 \%$ of your evaluation. Attendance will be taken. You will present your research at the end of the year to your colleagues and guests. Choose to research any topic or question you would like. I am not concerned whether you are successful or not; I want you to learn from what you do. I believe that if you really invest your time and energy into a project, and it does not work out the way you want it to-you will learn just as much as if it did. This is your time. I will not interfere. I will not be involved in meetings.

The first year went better than I expected. Most teachers seemed to be engaged. Some of the teachers clearly were not. In the middle of the year, I arrived for one of the meetings. The principal told me that the state department of education had rejected her use of teacher research as part of the evaluation plan for teachers. I gathered some research literature and shared it with her, and she wrote an argument for using the 
teachers' research projects as part of an assessment tool. She appealed the original decision and was granted permission to use teacher research as part of the evaluation.

In early spring of that year I learned to use a data analysis protocol through a session at the Knowles Teaching Science Foundation. I adapted and used this protocol with the teachers at the school. They seemed to feel this was helpful as they prepared to summarize and share their research projects. As we approached the end of the year, the principal called me up and asked, "Do you have a rubric for evaluating the research?" I did not-but assured her I would come up with one. So I developed a list of criteria and shared it with her to be used with the teacher research projects. She formatted it and made it into a rubric she could use for the projects.

Most of the teachers were not very happy about having to use www.merlot.org, and having to showcase their work with a multi-media portfolio. I have used this software often in my courses as an opportunity for students to showcase their learning in very creative ways. The software is set up to allow the school to collect all of the teacher research projects in one "library," that they can then access at any time, or give permission for those portfolios to be made public so that others can also benefit from their work. The principal supported my decision to use this to present the final project, and although resistant and complaining, the teachers all finished their multi-media portfolios before our "Research Festival." The teachers expressed feeling exactly the same way as I remember feeling before my first presentation: "My work isn't very good. I didn't finish. No one will be interested in what I have to say. Other people will not understand this, or might think it is not professional enough." At this point they were not so sure of the importance and legitimacy of teacher research.

Their initial studies were intriguing. One teacher decided to try a flipped classroom. He spent a great deal of time recording his "lecture" for math instruction, and assigned watching the video as homework. The next day in class, students were assigned problems to solve and could work together in small groups. He found the students preferred this method, because he was available for support, if they had questions or were confused.

Another teacher was trying desperately to find ways for students to make more meaningful journal entries about social studies topics. She worked on changing the way she asked questions, but was not satisfied. So with the help of a colleague she had students do individual video reflections and found students were much more willing to share. Then she had them respond in writing, and found that the writing improved. 
In both of these examples, teachers were trying to find what Dewey (1938) describes as "conditions that must be fulfilled in order that learning will naturally and necessarily take place, what conditions must be present so that pupils will make the responses which cannot help having learning as their consequence" (p. 266). It took a long time for teachers to come to define and refine the ideas and questions that they had, and much of this clarification came through the collaboration with others. The search for experiences that would not fall under Dewey's category of "miseducative" experiences (not wanting to stop or discourage learning), but rather to cultivate a "desire to go on learning" (p. 48) was the desired outcome to their research, and their students' learning.

This research festival was the first for the entire faculty. We held it offsite but in a nearby location. The teachers presented to an audience of their peers and invited guests. They each had only five minutes to briefly share their project portfolio. Interesting things happened as a result of this first research festival. First, the teachers who had been working together all year long had an opportunity to hear about their colleagues' final projects, and they were impressed by the work of their peers. Many claimed to have heard strategies and/or practices that they would like to implement the next year. Second, the guests were impressed and shared their appreciation and encouragement with the teachers. Lastly, one of the guests who was the superintendent of a small school district asked me if I would be willing to facilitate teacher research for K-8 teachers in that district.

\section{Principal's Perspective}

Our staff and faculty believe in the purpose and mission of the school and are deeply committed to that mission. To that end, all decisions, including those surrounding professional development, are in alignment with the mission of the school, and are determined by individual teachers' personal goals and data resulting from statemandated testing. As the principal, it falls to me to make sure that alignment occurs. To this end, we have implemented a comprehensive system of evaluating the impact of teachers in the classroom.

Based on a five-tiered evaluation system ranging from high impact in the classroom, to little or no impact in the classroom, teachers are evaluated four times per year, twice by administrative staff, and twice by neutral specialists affiliated with the local university. This, together with their students' improvement in their scaled state-mandated assessment scores, has determined their evaluation. The evaluation is data-based, and feedback is given after each observation, along with suggestions 
for improvement and a framework of support, so that classroom improvement can be implemented immediately.

In 2011, I was appointed by the governor of our state to the Effective Teaching Task Force. The Effective Teaching Task Force was formed with the purpose of delivering on the promise of recruiting, retaining and rewarding the state's most effective teachers. Over the course of three months, this 15-member Task Force met 10 times for over 60 hours to deliver recommendations to the governor.

To my dismay, I was placed on the "Professional Development Committee." To me, professional development was far too often inapplicable to the immediate classroom, if not downright painful. Our committee found, however, that the most effective professional development is also the most cost effective. Namely, professional development should be student centered and locally designed, its implementation the shared responsibility of the administrator and the teacher. All professional development should be informed by comprehensive data including, but not limited to, student achievement on standardized measures, results of informal assessments, observations, self-assessments, and surveys. Determination of success of the professional development must be partially determined by measurable increases in student achievement and professional reflection.

I have to admit, when I was first approached about starting a teacher research group, I did not leap in; it all sounded so "gooey" to me. As a data-driven school, committed to the school reform movement, there seemed to be too much subjectivity for my liking. However, it did appear to fit the qualifications of effective professional development. I was willing to have a small pilot group give it a try.

At the end of the year, the teachers presented their studies and I was hooked. Even though they came from different content areas and had different projects that were directly applicable to their students' classroom, the group came together in a spirit of common learning and problem solving. That is when I determined that next year the "Teacher Research Project" would be mandatory and a vital part of the total evaluation. As shown in Figure 1, each teacher's evaluation now consists of student improvement as determined by state-mandated assessment (50\%), observation (25\%), teacher research (15\%), and student survey (10\%). 


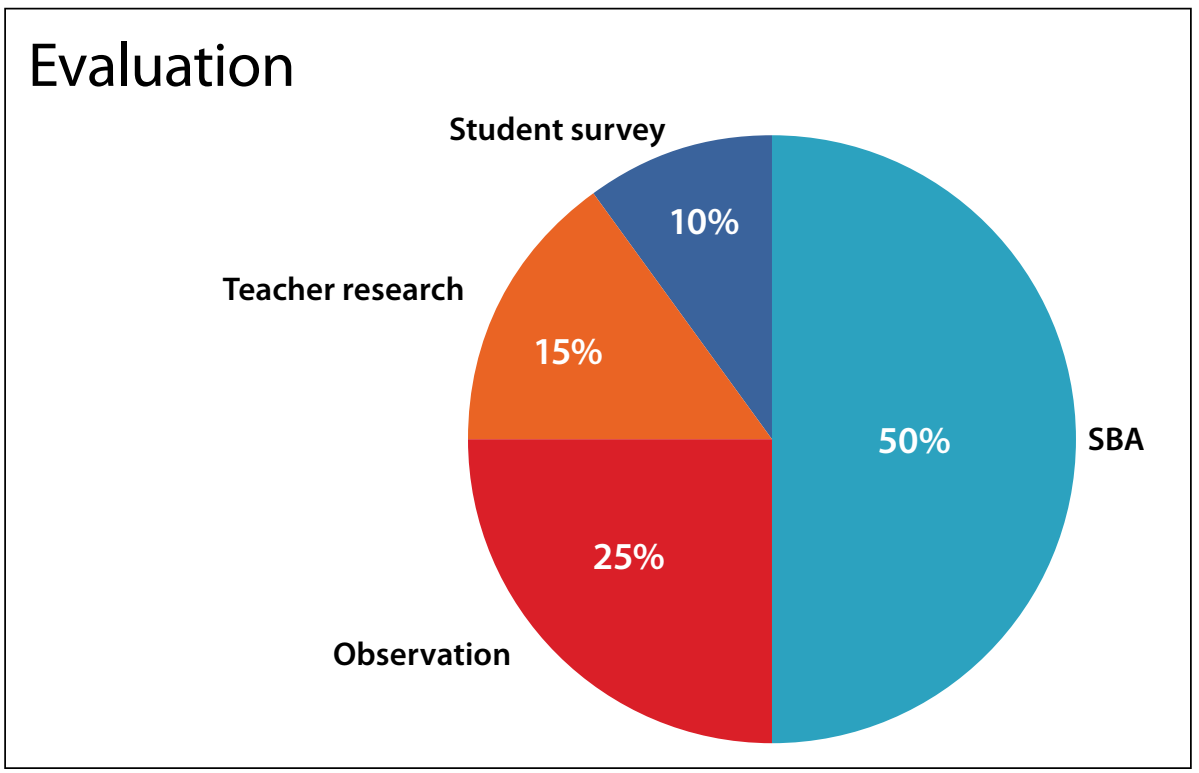

Fig. 1: Basis for teacher evaluation

Initially, the Public Education Department (PED) was not too impressed by Teacher Research either, and questioned my using it as a multiple measure. They felt the majority of the components (review of student work, planning, questioning, reflection, etc.) were already represented in the various domains of evaluation protocol. I would not have so ardently defended teacher research if I had not experienced it. It was not until I saw what it could do and the transformation that could happen, that led me to advocate for it as part of the evaluation. I did not mind fighting for it after this experience, and had to show that this was a reasonable thing to ask teachers for, that it was data based and not necessarily subjective on my part. Further explanation, however, helped the PED see things our way. We submitted the following:

Teacher Research can be summed up with the following:

What practitioners learn, however, can transcend immediate contexts. Those who bother to critically reflect on teaching and learning - to hold them up for collaborative questioning and systematic inquiry-can draw evocative lessons with the potential to resonate far afield. The lessons they learn and share won't provide justification for scripting teaching or creating recipes for "what works." The kind of knowledge that practitioner inquirers construct will be the kind of knowledge that can produce in others the shock of recognition, give them pause, inspire in them the will to try something similar, lead them to wiser and more informed and more intentional practices. (Wood, 2013) 
Additionally, the observations of the third party evaluators pointed to this practice as instrumental in the improvement of individual teaching practice:

We have noticed that over the last three visits, some teachers who had scored low in a number of areas of the Teaching and Learning Framework have demonstrated marked improvement. These improvements appear to be the result of the professional development work the administration has been offering.

Upon receiving their state-mandated assessment data, disaggregated by student and instructor, teachers meet together and ask themselves essential questions concerning their classrooms and student success. From this introspection, teachers develop potential interventions and classroom strategies, which are then immediately applied in the classroom and the results reported back to the group every other Friday. Through this process, teachers have identified "bright spots" of their practice and can fine-tune their teaching to replicate these areas of success, while at the same time identifying techniques that do not work as well, and altering or eradicating them from their classroom craft as appropriate. They present the results of their work at the end of each school year during the "Teacher Research Festival." The presentations are open to the community and parents as well. This year for the first time, individual teacher projects will be published. At our school, it is not about teacher or administration ego. It is about the common wisdom of the team utilized for the greater success of the student.

The impact of this system cannot be underestimated. Almost immediately we saw our reading and math scores increase each year, from $37 \%$ and $40 \%$ proficiency, respectively, to the current proficiency rate of $96 \%$ for both reading and math. The greatest improvement has been in my "Level 1" teachers or teachers with 0 to 3 years of teaching experience. These teachers were able to improve their evaluation scores from, in some cases, "ineffective" to "highly effective." 


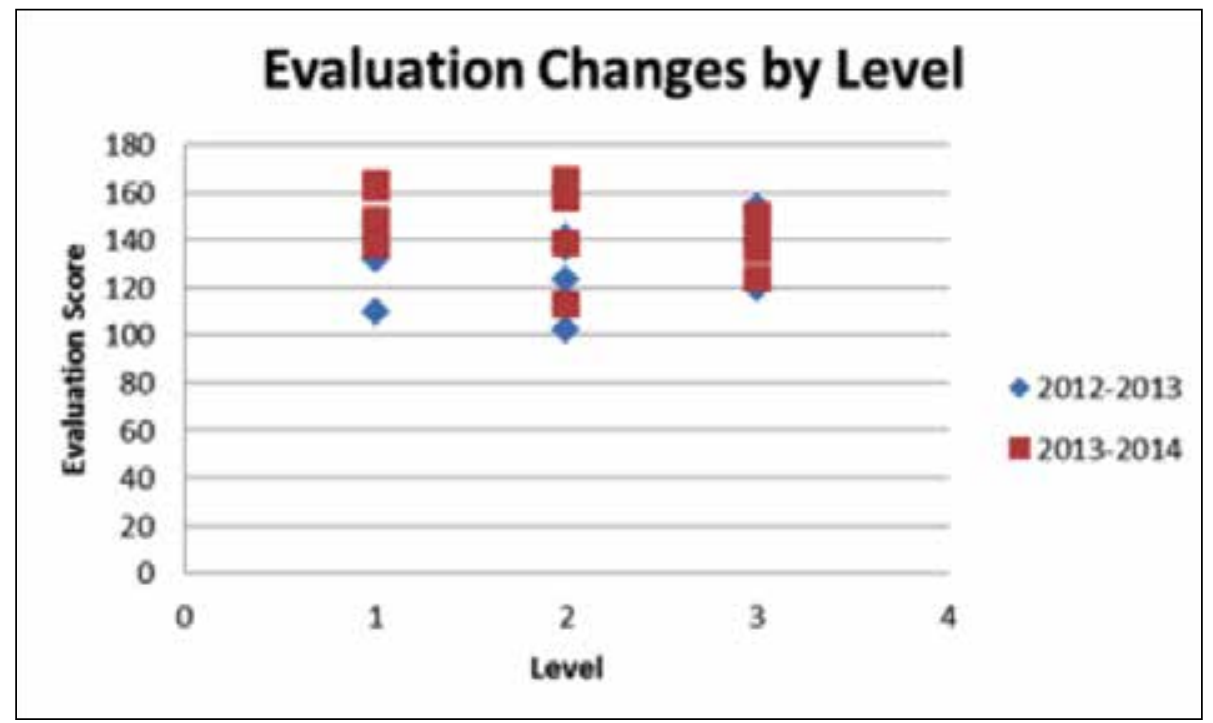

Fig. 2: Changes in teacher evaluation scores by level of experience

One teacher in particular comes to mind. This teacher was not only ineffective in the classroom, but was also miserable and considering leaving the profession altogether. In many cases, the students' scaled scores were getting worse while in her class. Figure 3 shows the data points of her students' scaled scores. Students above the "0" improved in performance, those below got worse.

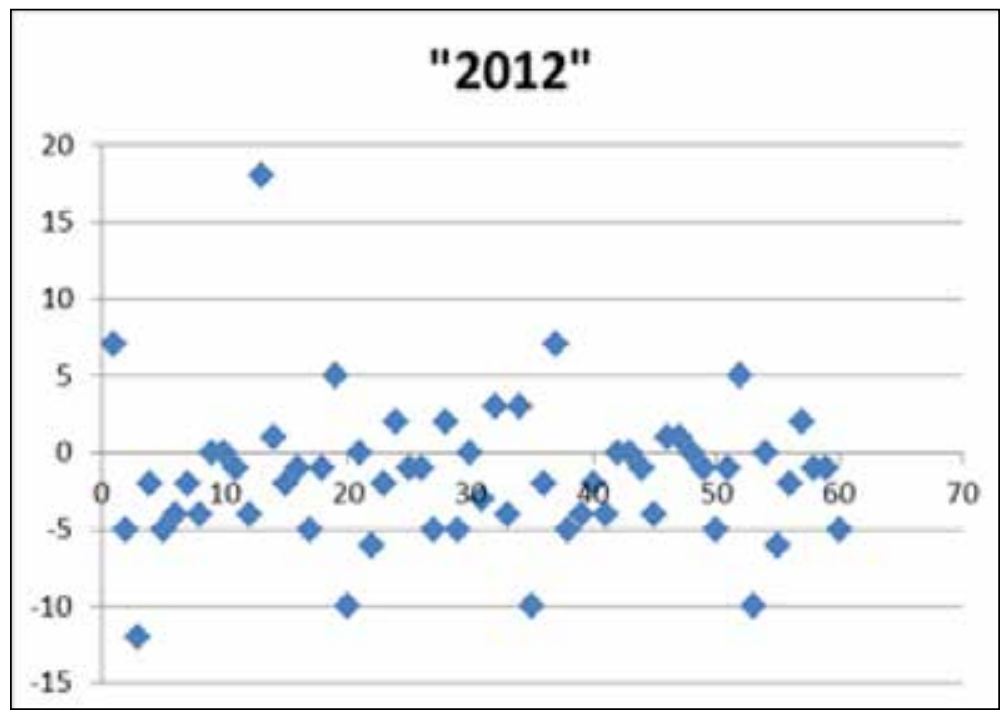

Fig. 3: Student scaled scores for a level 1 teacher 
That year, this instructor decided to give the profession another chance. She decided to look at ways she could "lead from behind rather than in front" (she was known for having an autocratic style). Together with her colleagues, she developed strategies she could immediately implement in her classroom. The next year saw a different story in her students' performance. The vast majority of her students improved.

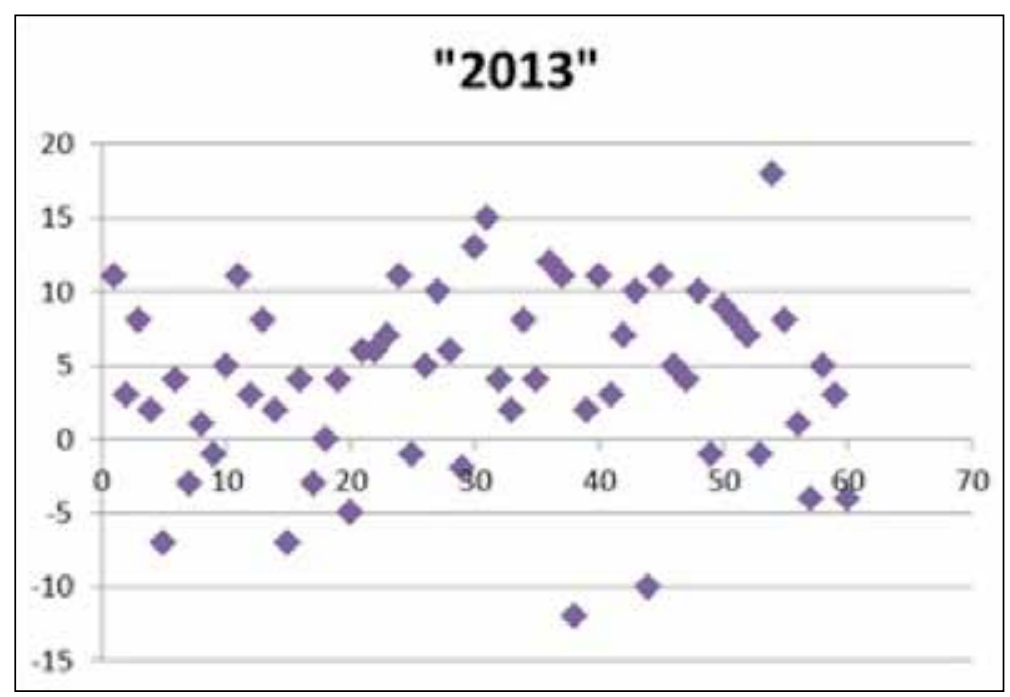

Fig. 4: Student scaled scores for this level 1 teacher the following year

Her student surveys were also impacted. Prior to her project, her survey responses were far below the school average. Comments like "I wish she liked us more" or "I wish she was kinder" were common. Her lowest score was in response to the comment "My teacher really tries to understand how students feel about things." The next year saw dramatic improvement in her students' responses. 


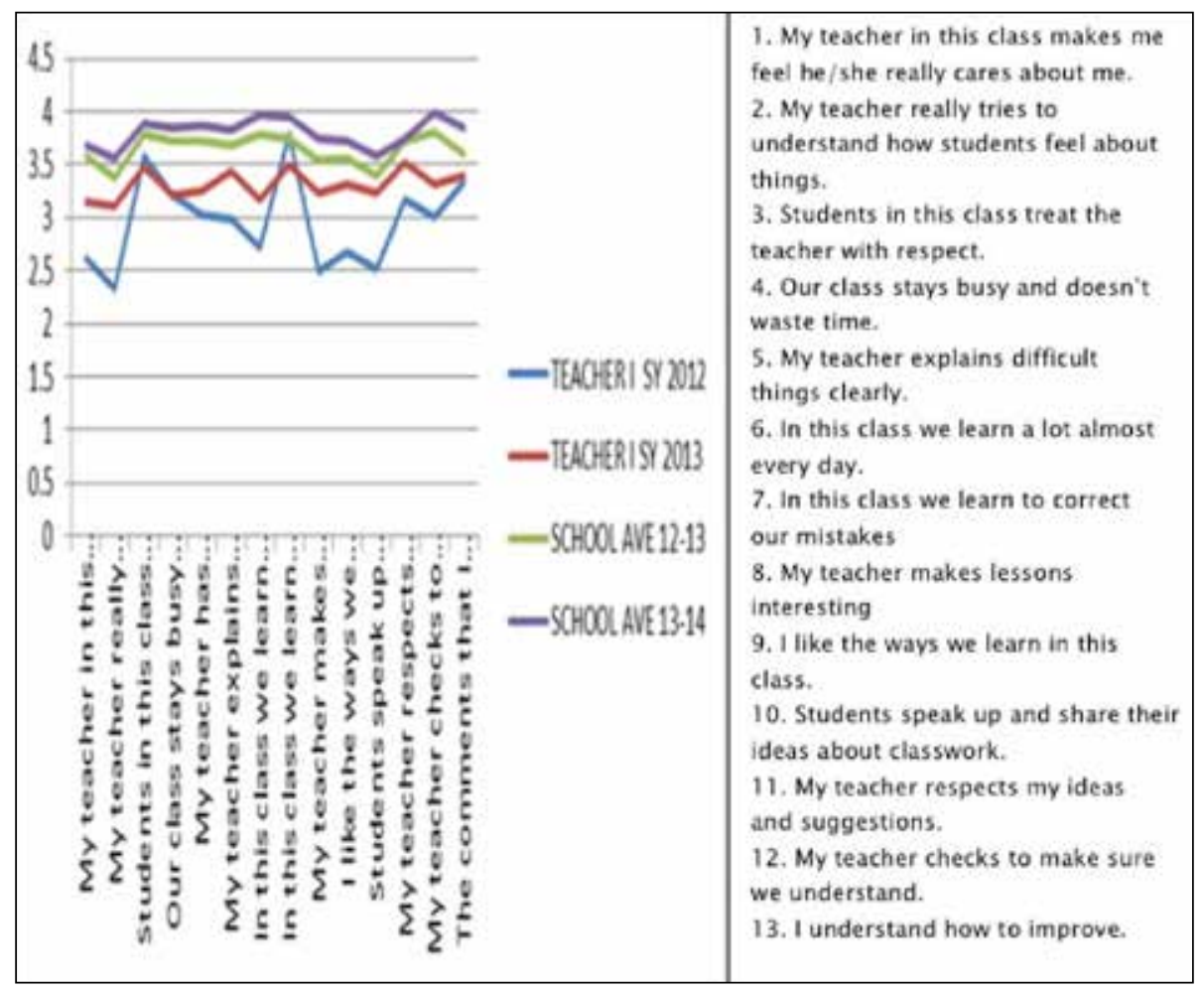

Fig. 5: Student survey results for level 1 teacher and school average

True, the teacher is still below the school average, but she is getting better. More importantly, she is still in the profession and she reports she is happier. Also of note is the school average continues to improve.

Today the school is still focused on continuous improvement. In 2013, our school became one of only 11 charter schools to be recognized as a Blue Ribbon School. In 2014, the school was ranked 48th in the nation of all public and private schools for rigor by the Washington Post. It was ranked 64th in the nation and first in the state of all public and private schools for college preparation by US News and World Report; among only national charter schools it was ranked 17th. Newsweek ranked the school in the top $25 \%$ of the best 2000 schools in the nation. Most rewarding, however, is the performance in the lowest performing $25 \%$ of our students. In the past three years the school grade for the lowest performing $25 \%$ of our students went from a letter grade of D in 2012 to a letter grade of B in 2014. I cannot lay the success and improvement solely 
at the feet of the Teacher Research Project, but I am fairly confident a good portion of the credit goes to this initiative.

\section{Reflection and Future Goals}

As we reflect together on this experience, we are looking forward to its replication. The principal has been given funding to replicate this school in another location. She states, "For the future, as we replicate to different campuses, the teacher research will be replicated as well." Replication is by definition replication of the entire program, not just elements of it. This requires the same: leadership, board, teaching methods, discipline, traditions, mission statement, and teacher research. Teacher research is part of the school's way. Teachers have been immersed more deeply into the unique lives of their students and their students' thinking. They have modified practices because of their intentional look at what is happening in their classrooms. They have created through their multi-media portfolios, kept in one library online that all teachers can access, what Dewey (1928/1956) asks for: "A series of constantly multiplying careful reports on conditions which experience has shown in actual cases to be favorable or unfavorable to learning..." (pp. 125-126). By sharing these portfolios they are also attending to what Shulman (1999) emphasizes as a quintessential part of the scholarship of teaching and learning, sharing practice with others so that it can be critiqued by peers, and potentially influence their own practices. As Hashweh (2003) found, this process has given teachers the opportunity to:

remain open to new pedagogical possibilities while recognizing their limitations; construct new knowledge and beliefs; develop their ideas and put them into practice; synthesize new with prior ideas that had been valuable; and collaborate with colleagues and possibly university educators in order to maintain a support system. (p. 428)

We also believe that we have affirmed what Cochran-Smith and Lytle (2009) described: The emic perspective of teachers as knowledgeable experts is privileged. The change that occurs is not from the top down, but organic, from the classroom, led by teachers. Teachers as professionals take an inquiry stance in their own context. Their practitioner knowledge is both valid and generative, and the research and practice boundaries have been blurred. Teachers claim to feel empowered and energized by the process. A strong community and shared respect has emerged.

We do agree that the first-year voluntary "pilot" of this project was beneficial, and most probably necessary. In our initial conversation, the principal repeatedly asked 
what were the criteria the teachers would be held accountable for? How would she know if they had done the work? She felt the idea was fuzzy or nebulous, not well defined. This is true, especially in teacher research when each individual teacher's question is personal and unique to their classroom setting. We had no idea how this would turn out, but the university facilitator felt strongly about the value of teacher research from many years of experience. The university facilitator gave the principal a copy of "Teacher Research: Stories of Learning and Growing" (Roberts, Bove, \& van Zee, 2007) as examples of others' teacher research projects. The principal reluctantly acquiesced, her agreement led to other obstacles as she tied this to teacher evaluation in the second year. Because of what the principal had observed during the pilot, she was willing to advocate for teacher research to be accepted by the state as part of teacher evaluation.

From this experience we believe that it is important to try this first with a group of teachers who are willing, because their energy and enthusiasm is evident and contagious. With a few teachers who "get it," it is more likely that others will be willing to participate and see the value. This is especially true when collaborating with principals who have not yet seen the transformative power of teacher research. This is a "replication" of our first (and continued) experiences in teacher research. We have come full circle!

\section{References}

Boyer, E. L. (1990). Scholarship reconsidered. San Francisco: Carnegie Foundation for Advancement of Teaching.

Bullough, R. V. J., \& Pinnegar, S. (2001). Guidelines for quality in autobiographical forms of self-study research. Educational Researcher, 30(3), 13-21.

Carr, W., \& Kemmis, S. (1986). Becoming critical: Education, knowledge and action research. New York: Taylor \& Francis.

Cochran-Smith, M., \& Lytle, S. (1993). Inside outside: Teacher research and knowledge. New York: Teachers College Press.

Cochran-Smith, M., \& Lytle, S. L. (2009). Inquiry as stance: Practitioner research for the next generation. New York: Teachers College Press.
Dewey, J. (1928/1956). Progressive education and the science of education. In M.S. Dworking (Ed.), Dewey on education selections (pp. 113-126). New York: Teachers College Press.

Dewey, J. (1938). Experience and education. New York: Simon and Schuster.

Hashweh, M. Z. (2003). Teacher accommodative change. Teaching and Teacher Education, 19(4), 421-434.

Roberts, D., Bove, C., \& van Zee, E. (Eds.) (2007). Teacher research: Stories of learning and growing, Arlington, VA: NSTA Press. 
Samaras, A. P., Hicks, M. A., \& Berger, J. G. (2004). Self-study through personal history, in J. J. Loughran, M. L. Hamilton, V. K. LaBoskey, \& T. L. Russell (Eds.), The international handbook of self-study of teaching and teacher education: Practices. Dordrecht, The Netherlands: Kluwer Academic Publishers.

Shulman, L. (1999). Course anatomy: The dissection and analysis of knowledge through teaching. In P. Hutchings (Ed.), The course portfolio: How faculty can examine their teaching to advance practice and improve student learning (pp. 5-12). Washington, DC: American Association for Higher Education. Retrieved from: http://frontpage.uwsuper. edu/scholars/SchulCA.pdf
Shulman, L. S. (2004). The wisdom of practice: Essays on teaching, learning, and learning to teach. San Francisco: Jossey-Bass.

Wood, D. (2013). Opening Comments for KSTF Practitioner Inquiry For A New Generation. Data Analysis Consultation Sessions held in Moorestown, NJ.

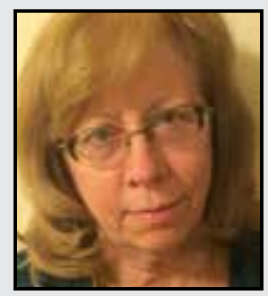

Deborah Roberts-Harris is a long-time teacher researcher and teacher research advocate committed to empowering teachers through studying their own practices. She spent 15 years teaching in grades 1-8, has been a science curriculum specialist at local and state levels, and currently is an assistant professor at the University of New Mexico where she teaches courses on elementary science teaching methods and social justice. Collaborating with teachers at a local charter school and in a rural school district, as well as with students in her classes, motivates and inspires her continuing commitment to teaching and teacher education. 


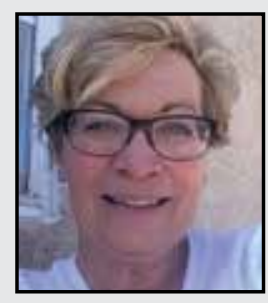

Kathy Sandoval has a long history in the Albuquerque educational community as an innovative educator. Under her leadership, AIMS@UNM changed its name, partnered with UNM, included a college-bound mission, added a middle school, increased the rigor of the curriculum including AP classes, secured a facility on UNM campus, more than doubled enrollment, tripled dual credit enrollment, secured a global staff, curriculum and student body. Ms. Sandoval received the 20072008 Outstanding Educator of the Year. She has also taught all levels of Math, Chemistry, Physics, AP Physics, AP Biology, Premedical Science, Advanced Pre-Medical Research Techniques, and Astronomy. 